\title{
Analysis of the Barriers and Countermeasures of the Scientific and Technological Achievements Transformation in the Institutes of Colleges and Universities ---- Taking Dalian as an Example
}

\author{
Jihui Sun ${ }^{1, a}$ and Xiujuan Ren ${ }^{1, b}$ \\ ${ }^{1}$ School of Economics and Management, Dalian University, Dalian, China \\ adlsunjihui@163.com, b36728031@qq.com
}

Keywords: Institutes of colleges and universities; The transformation of the scientific and technological achievements; Local transformation; Counter measures.

\begin{abstract}
With the development of economic globalization, science and technology level has become a standard of national comprehensive strength. Transformation of scientific and technological achievements in our country, however, is not optimistic, local transformation is rare either. This paper takes Dalian as an example, found that although annual scientific research investment in Dalian academics is more than 3 billion yuan, the rate of actual local scientific and technological achievements transformation is low, the real industrialization products and scale is also insufficient. We used the questionnaire survey to find out the barriers of scientific and technological achievements' local transformation in Dalian and provide the corresponding solutions.
\end{abstract}

\section{The Concept of Scientific and Technological Achievements and Its Transformation}

The Concept of Scientific and Technological Achievements. Scientific and technological achievements is a proper noun in management of science and technology. In China, it is defined as creative results in science and technology, which has the using value. It is generated by the broad sense and narrow sense [1]

Due to the science and technology activities involve in research and development, scientific and technological achievements transformation, application and service, so scientific and technological achievements should include these kinds of activities results. In recent years, soft science valued day by day, it's achievements is included. So in a broad sense, scientific and technological achievements is divided into basic theory, application and technological achievements and the soft science [2]

Now we definite the scientific and technological achievements into application and technological achievements in a narrow sense, according to the law of "People's Republic of China on Scientific and Technological Achievements Appraisal Method " in 1994, and the law of "People's Republic of China to Promote Scientific and Technological Achievements Conversion" in 2015 modified. It doesn't include basic theory and the soft science [3]

The Concept of Scientific and Technological Achievements' Transformation. Correspond to the scientific and technological achievements, the transformation of scientific and technological achievements has broad sense and narrow sense too. In a broad sense, it includes results of all kinds of applications, from production of knowledge to the final productivity, such as basic research of the spread of new knowledge, new theory, application technology of new products, new materials, soft science research for government and so on[4]

In a narrow sense, the transformation of scientific and technological achievements mainly focus on the innovation of the end of the chain, namely the application technology transform to the realistic productivity which will get economic benefit.[3]

\section{The Data Collection and Analysis}

Data Collection. From a narrow perspective, this paper believes that the transformation of 
scientific and technological achievements is the transformation of application technology, includes technology and patent transferred revenue. According to the ministry of finance on the scope of transformation of scientific and technological achievements, the capital source is divided into vertical and horizontal subject. Therefore, this paper analyzes funds investment with technology and patent transferred revenue which university institutions obtain. We use Dalian University of Technology, Chinese academy of sciences, Dalian Maritime University, Dalian Jiaotong University, Dalian Polytechnic University, Dalian Ocean University, Liaoning Normal University and Dalian university as the research object, then collect relevant data between 2006 and 2013, design the questionnaire survey at the same time.

Data Analysis. From the project sources, we see the funds 9.42 billion yuan from nation, province, municipality and the enterprises. It shows an increased trend year by year. Among them, 4.6 billion is from nation and province, 220 million is from Dalian municipality, 1.07 billion is from Dalian urban enterprises, 3.53 billion is from Dalian foreign enterprises. It is obvious from the data, the national and enterprises funds input for up to $97.66 \%$ of the total funds. Nation and enterprise attach great importance to scientific and technological achievements, however, municipal government inferior.

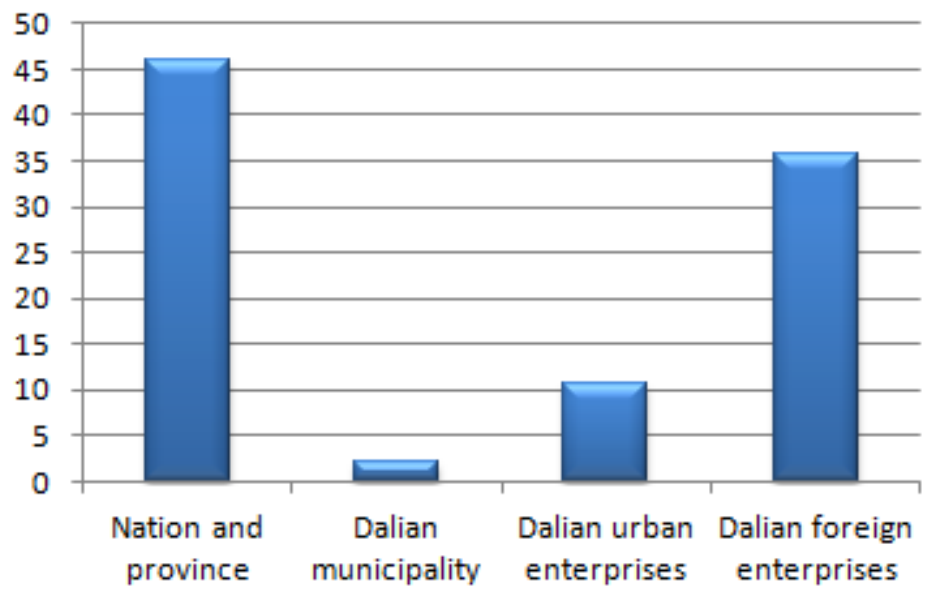

Figure 1. The project sources

This eight universities and institutes from 2006 to 2013 applied 9600 invention patents, 3780 are authorized, the rate is $39.4 \%$. 484 are transferred, the rate is $12.8 \%$. The transformation to the Dalian urban enterprises and institutions is about 155 invention patents, $32 \%$ of the total number, $15.3 \%$ of the total transfer amount.

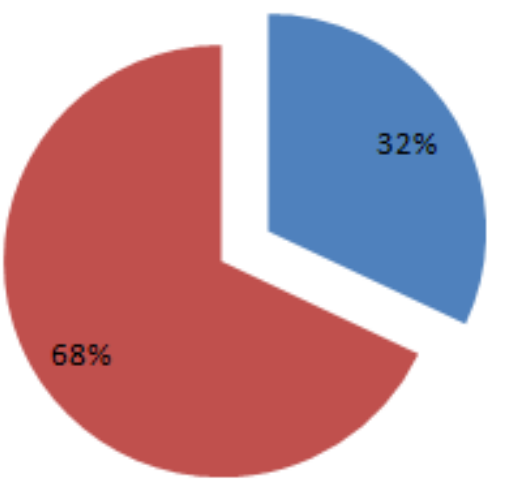

$$
\begin{aligned}
& \text { Amount of urban } \\
& \text { Amount of foreign }
\end{aligned}
$$

Figure 2. The transferred rate of patents 
From 2006 to 2013, the eight universities and institutes are identified 438 items of scientific and technological achievements, the technology transfer contracts are 744 items. The transfer contracts to Dalian enterprises are 154 , accounting for $20.7 \%$. The deal amount is 122.55 million, accounting for $12.5 \%$ of the total turnover.

In short, from 2006 to 2013, the eight universities data, Dalian local scientific and technological achievements conversion rate is really low.

The Questionnaire Analysis. To summarize the reason, we do a questionnaire survey in Dalian, the university area and person involved institutions, enterprises, government leaders and the scientific researcher. We have distributed 200 copies of questionnaires, take back 176 pieces, valid questionnaires are 176 copies. Through questionnaires, we analyze the problems that enterprises and universities encountered in the process of transformation.

Lack of awareness: $3.2 \%$ of people think school leader and researchers in Dalian university exist deviations in understanding the transformation of scientific and technological achievements, and lack the sense of the development.

Lack of talents: $12.9 \%$ of people think that research personnel ability in Dalian university is low and scientific researches lack experience, research is rare in professional engineering and technical personnel participation.

Away from the actual: $47.81 \%$ of people think that the transformation of scientific and technological achievements divorce the actual is the main reason of the low conversion rate. Such as the Dalian Ocean University, has developed a rearview mirror, which has many functions such as navigation, driving record. However, it was not in the market, because the cost increased, consumer spending also increase. Product design is away from enterprise and market, so the research mostly stay in the laboratory or test phase.

Risk problem: Risk issues accounted for $6.16 \%$ of the overall, including moral risk, market risk, property risk, etc.

Insufficient funds investment: $14.13 \%$ of people think that Dalian government devotion to research on the low side, it is correspond to the data we collected from 2006 to 2013.

Government policy: $15.8 \%$ of people believe that the policy of local government is the important factor affecting the local transformation of scientific and technological achievements. From the formulation, market monitoring system to the ownership issue of scientific and technological achievements, scientific researcher incentive problem, etc., there are many details remain to be improved.

\section{Countermeasures and Suggestions}

Guidance Measures. 1. From the perspective of the talent, we should make all kinds of talent plans, support the winner of the "award for science and technology achievement", "technology award", "science and technology progress prize" and other high level talents in Dalian transform the scientific and technological achievements, explore the introduction policy of support outside talent.

2. Guide university institutes, establish and perfect the system of leadership and decisions for the major issues of the transformation of scientific and technological achievements, grasp the difficulties and problems during the transformation in time. One project one discussion, simplify the procedures and solve the problems timely.

3. Encourage and support enterprises in Dalian carry out exchanges and cooperate with foreign universities, research institutes and high-tech enterprises, improve the ability of technological innovation through mergers and acquisitions. Build university-enterprise institutes and research center between colleges, and transform the scientific and technological achievements in Dalian.[5]

Incentives. 1. Allow the scientific research team to purchase the equipment that horizontal object is necessary. Allow researchers extracted 50\%-70\% service fee from horizontal topic funds.[6]

2. Make full use of the stake sale, stock options, project profit share, post bonus to incentive scientific and technological personnel to transform the scientific and technological achievements. 
Rewards that science and technology personnel acquire, can take 5 years in installments for personal income tax, or pay individual income tax when pay dividends. For people who carry or use their professional advantage to start a business, enterprises can keep human relations for three years.[7]

3. In the performance evaluation of university institutes, transformation of scientific and technological achievements shall be as one of the evaluation index. According to the transformation of scientific and technological achievements of the annual report, evaluate the unit transformation and reward the performance of outstanding units.

4. Fully implement the fee policy of enterprise additional deduction, adjust the catalog management style. At the same time, enterprises enjoy the preferential tax policy of research and development costs as the application technology of check and ratify the important condition of project.

Safeguard Measures. 1. Establish enterprise and social investment, colleges and universities combination of diversified investment system, support colleges and universities independent innovation and integration. Universities in Dalian shall transform the scientific and technological achievements in local city, promote local transformation. [8]

2. Promote the development of science and technology intermediary service institutions. Strengthen the construction of industrial technology innovation comprehensive service platform, play the role of technology industry association, cultivate a batch of famous technology service organizations and backbone enterprises, make the marketization research and intermediary service agencies.

3. Strengthen the basis of the transformation of scientific and technological achievements. Set up the technological database orient Dalian science and technology. Foster technological market, promote technological achievements trade, adopt the mode of online, innovate financial products and services, strengthen the interaction of the online technology market and technology trading market [9]

4. Improve the quality of financial service of science and technology. Play full their role in the industry investment in Dalian, support and encourage each unit set up financial service platform, set up a branch of science and technology, scientific and technological insurance, lease of science and technology, science and technology of small loans and guarantees and so on.[10]

5. Enhance the level of intellectual property services. Establish intellectual property information service platform in Dalian, improve the protection mechanism of intellectual property, effectively protect the lawful rights, promote intellectual property to analysis evaluation, operation implement, investment and financial service level.

\section{References}

[1] http://www.lninfo.gov.cn/

[2] D.F. He: Strategic Decisions, (2011)No.11,p.1.(In Chinese)

[3] http://law.lawtime.cn/d706304711398.html

[4] X.J. Zou and Y. Cheng: promoting mechanism of transformation of scientific and technological

[5] achievements in colleges and universities study(MS, Zhejiang university, China2012),p.1.(In Chinese)

[6] X.M. Kang: Journal of China University of Science And Technology,Vol.1 (2014)No.8,p.82.(In Chinese)

[7] L. Lan:Chinese University of Science And Technology, Vol.1 (2013)No.Z1,p.40.(In Chinese)

[8] W. Hui: Chinese University Science And Technology, (2015)No.8,p.75.(In Chinese)

[9] X.J. Ma and C.W. Pan: Modern Education Management, Vol.1 (2015)No.1,p.78.(In Chinese) 
[10]Y. Li and Y.N. Gao: University of Science And technology Innovation Efficiency And Influencing Factors of Empirical Research (MS, Nankai University, China2010),p.1.(In Chinese)

[11]J. Dong and F. J. Huang: Soft Science, Vol.26 (2012)No.10,p.15.(In Chinese) 